\title{
Effect of Networking on Performance of Small and Medium Scale Enterprises in Benue State, Nigeria
}

\author{
EKEH Loveday Ojotu ${ }^{1 *}$, TSETIM James Tersoo² and OGUCHE Michael Kenneth ${ }^{3}$ \\ 1Department of Business Administration, Benue State Polytechnic Ugbokolo, Benue State, Nigeria \\ 2Department of Business Administration, Federal University of Agriculture, Makurdi, Benue State, Nigeria \\ ${ }^{3}$ Department of General Studies, Benue State Polytechnic Ugbokolo, Benue State, Nigeria

\section{*Corresponding Author} \\ Ekeh Loveday Ojotu
}

\section{Article History}

Received: 07.12.2019

Accepted: 15.12 .2019

Published: 25.12 .2019

\begin{abstract}
This study was carried out to examine the effect of networking on the performance of Small and Medium Scale Enterprises (SMEs). The study focused on SMEs in Makurdi metropolis. The study specifically examined the effect of network structure, network governance and network content on the performance of SMEs in Makurdi, Benue State. The study adopted the survey research design due to its ease of application and the speed with which its results are ready. The target population for this study consists of 708 owners/senior management staff of SMEs in Makurdi metropolis in Benue State, Nigeria. These consisted of different sectors like food processing (24), livestock rearing (32), schools (86) trading (164), art/craft (42), baking (34), table water (17), fashion and designing/ hair dressing (97), ICT (92), health (65) and transportation (55). 256 respondents were sampled. The questionnaire was used as the research tool for data collection. The research tool consists of two 4-point Likert questionnaires. The 256 questionnaires administered met a 0.83 response rate and 213 questionnaires were used for statistical analysis. With the aid of SPSS version 21, multiple regression analysis was used to test the strength of the effect of network dimensions on performance of SMEs. Findings of the study revealed that network structure has significant effect on the performance of SMEs in Benue State and network governance has significant effect on the performance of SMEs in Benue State. Also, the result indicated that network content has significant effect on the performance of SMEs in Benue State. The study concluded that the structure, governance and content of networks maintained by SMEs have significant effect on their performances. Recommendations were made among others that, management of SMEs should be mindful of the content of their networks since the network content has significant effect on the performance of SMEs.
\end{abstract}

Keywords: Network structure, Network governance, Network content, SMEs performance.

\section{INTRODUCTION}

Today, most organizations have limitations in terms of resources they possess internally. They are faced with massive globalization, demanding customers with rapidly changing desires, shrinking response time, shrinking product lifecycles and demanding employees. This requires organizations to become fast, flexible, and participative and focused on customers, competition, teams, time and process [1]. In this regard, if an organization can network with its suppliers, buyers and competitors, it becomes a crucial ingredient to avoid competition and achieve advantage [2, 3].

The tendency therefore has been to develop some external linkages that act as conduits through which they can gain access to those resources possessed by others. In this regard, networks can serve as a way to increase their core competences in innovation by partnering with complimentary firms [4]. Nyangarika [5] asserts that for SMEs, networks are regarded as a means of providing diversity of knowledge, accessing resources and complimentary assets. In addition, firms that emphasizes on building business networks increase flexibility and efficiency [6,7], access network resources at minimal transaction cost [8], operate under reduced business risk [9], and eventually their performance is high [10].

Networking can be viewed as the process of building long term contacts with the motive to have access towards information and resources [11]. Chetty and Wilson [12] argue that inter-firm network provide firms access to a variety of important resources and

Copyright @ 2019: This is an open-access article distributed under the terms of the Creative Commons Attribution license which permits unrestricted use, distribution, and reproduction in any medium for non commercial use (NonCommercial, or CC-BY-NC) provided the original author and source are credited. 
complementary skills which leads to the building of specialized knowledge and achievement of economies of scale in operations and collaboration to acquire greater knowledge and capabilities. Though there are accrued benefits in regard to networking, SMEs are not motivated to seize the opportunities to networking [13] There is evidence from literature that network relationships play a role in the SMEs performance. Distinct characteristics in network relationships such as structure, content and governance significantly affect the performance of small and medium enterprises.

Through networks, organizations are able to identify opportunities, raise resources, achieve competitive advantage and hence achieve overall improved performance. Individual SMEs experience difficulties in achieving economies of scale in purchase of inputs and are often unable to take advantage of market opportunities that require large production quantities, homogenous standards and regular supply $[14,15]$. It is generally acknowledged that isolation, rather than size, is the key obstacle, preventing SMEs boosting their competitiveness. Networking therefore offers an important route for individual SMEs to address their problems as well to improve their competitive position [16].

This study beholds networking in three dimensions; network structure, network governance and network content. Network structure is defined as the pattern of ties between different actors [17]. Network governance is the element of coordination of the network exchange [18]. It is the mechanism that governs the relationship among actors, the legal forms of actors, and the incentives for participations within networks. Content within a network refers to exchanging resources [19]. Business performance reflects firm growth and capability, signifying outcomes over time, and the development of organizational capability from a complex blend of networks, knowledge, and innovation [20]. In this study, business growth and responsiveness to change are employed as measures of business performance, as suggested by Stafford et al., [21].

In Benue state, Nigeria, the increasing economic hardship has made SME development programs a priority in for economic growth and poverty alleviation. A significant number of SMEs in Benue state fail and one of the key challenges in regard lies in addressing the entrepreneurs' lack of understanding regarding networks and the role they play in a successful entrepreneurial process. Therefore, this research assessed the impact of networking on performance of SMEs in Benue State, Nigeria.

\section{THEORETICAL FRAMEWORK}

This study is based on certain relevant the social network theory that form the backbone of ideas which provided the super structure that culminated in the development of research questions and construction of hypotheses tested. The strands of arguments on the basis of these theoretical paradigms are discussed below.

\section{The Social Network Theory}

The social network theory introduced by Moreno [22] argues that individuals in any society are involved in a number of social relationships with each other. Coleman [23] argues that within a society/group marked by a high degree of social disintegration, trustworthiness among members will be low and the value derived from such connections is not great. Therefore, members will seek to form linkages and networks. This will result in mutual bonds among members creating trustworthiness which leads to beneficial information and resource exchanges. Burt [24] proposes the structural holes theory which suggests that an individual is in an advantageous position to acquire information if he/she is connected to others who are not directly connected to each other. This forms the basis for individuals forming linkages or networks with other individuals or firms. Therefore, a manager who spans the structural holes by having non-redundant contacts on both sides of the structural hole will have access to different beneficial information flows [25].

\section{CONCEPTUAL CLARIFICATIONS AND HYPOTHESES DEVELOPMENT Concept of Networking}

Networking in a small firm context could be defined as activities in which the entrepreneurially oriented SME owners build and manage personal relationships with particular individuals in their environment [26]. The concept of networking includes four components: actors; links; flows and mechanisms [27]. The actors are the individuals and entities who make up the network. Links or ties are the arches that connect individuals and represent the relationship between actors. The flows indicate the exchanges that occur between the actors within network and largely involve flow of resources. Finally, the mechanisms of the network are the modes and rules of interaction employed by actors within the network [28].

Networking encompasses all of the interactions of a company or individual in the Network [29]. Networking is now used to describe new forms of interaction between organisations, large and small, as the boundaries around firms come to be seen as less sharp than was once assumed, with firms engaging in networking activities [30]. Networking is part of the complex and continuous interaction that takes place and the outcomes will often become blurred. Companies learn from networking and their subsequent choices in networking are affected by how their outcomes develop [29].

Firm networks appear to be strategically significant as the networking process can be the enactment of the environment [31]. A network is defined as a collection of relationships that binds a group of independent organizations together [32]. Hoang and Antoncic [18] defined it in broadly, as a set of actors (individuals or organizations) and a set of linkages between the actors. Casson 
and Giusta [8] proposed that a set of elements that are connected to each other form a network. According to Casson and Giusta [8], elements can be regarded as members (actors) of a network, with each pair of members being connected, either directly or indirectly, creating connections or relationships between members.

Network relationships in business are distinguished as purposeful networks, consisting of specific roles and value interactions oriented toward the achievement of a particular task or outcome [33]. Active agents of a network participate by playing particular roles in which they convert both tangible and intangible assets into negotiable offerings and fulfil different functions. The definitions of network relationship vary, but essentially depend on whether the primary focus is on the configuration of ties (i.e., the structure of relations among actors) or on the quality of relationships between actors within linkages [34, 35].

\section{Dimensions of Networking}

Networking relationships can be viewed in three perspectives: structure, governance and content $[19,18]$. Allee [33] suggest that network relationships in business are distinguished as purposeful networks consisting of specific role and value interactions oriented towards the achievement of a particular outcome.

\section{Network Structure}

Network structure can be defined as a pattern of relationships that is engendered from direct and indirect ties between actors [18]. Network literature has considered embeddedness of firms in networks of external relationships with other organizations crucial [9] and has emphasized the importance of external resources and capabilities to the firm through its networks [36, 37]. Hoang and Antoncic [18] posit that within a network structure, network size and centrality determine the amount of resources an actor can access. In addition, network structures centre on differential network positioning that exerts an influence on resource flow [18, 35]. Since structure influences resources flow, a clearly defined structure is likely to influence performance.

Network structures centre on differential network positioning that exert an influence on resource flows as well as on entrepreneurial outcomes [18, 35]. Within a network structure, network size and centrality determine the amount of resources an actor can access [18]. The network structure of social ties has been the focus of network theoretical approaches to social capital [34], revealing the important effects of structural features of closed networks (where all of an individual's important contacts know each other) and structural holes (where an individual's contacts are mostly unacquainted) [38, 39, 35, 36].

Burt [39] argued that the benefit of social capital stems from non-redundant ties, as structural holes exist from the absence of ties among those to whom one is connected (unacquaintance), which could provide access to different, non-redundant sources of information and resources. Moran [35] contended that both closed networks and structural holes can be simultaneously accommodated in some organizational contexts. Besides, the presence of structural holes in networks can challenge the ability of actors to gain access to a diversity of resources [18].

\section{Network Governance}

Governance is based on the mechanisms that coordinate, undergird, or support resource exchange within networks [18]. Governance ties are reinforced by mutual feelings of attachment, reciprocity, and trust, supporting a commitment to resource exchange within network ties [40]. Network governance helps to explain the reliance on implicit and open-ended contracts supported by social mechanisms (e.g., power, influence, threat of isolation, loss of reputation) rather than by legal enforcement [18].

Network governance is the element of coordination of the network exchange [18]. It is the mechanism that governs the relationship among actors, the legal forms of actors, and the incentives for participations within networks. These mechanisms are based on power, influence, relationship reciprocity, and trust support the network sustainability more than legal enforcement [19]. Larson [41] posits that reciprocity refers to mutual connection between two actors within a directed network. Proper coordination of the network exchange is vital for enhanced firm performance.

\section{Network Content}

In regard to network content, business networks are viewed as enabling actors to gain access to a variety of resources, held by other actors through interpersonal and inter-organizational relationships [18]. In uncertain and dynamic conditions in which entrepreneurial activities occur, networks can help to gauge the underlying potential of ventures by creating beneficial resource exchanges. Reliance on networks is not restricted to the start-up stage, but continues throughout all stages of development.

Content within a network refers to exchanging resources [19]. Research on networks often adopts resource based view of the firm and views firm as dependent upon the external environment to prove resources and capabilities as opposed to normal market transactions. These resources vary and include: advice [42], encouragement and financial resources [43], contacts [44] and legitimacy [45]. Further, resources may also include ideas, information and advice [46]. Resources are major constraint hindering SMEs performance, when they are acquired sustainably the implications is enhanced firm performance. 


\section{Concept of SMEs Performance}

Business performance reflects firm growth and capability, signifying outcomes over time, and the development of organizational capability from a complex blend of networks, knowledge, and innovation. Slotte-Kock and Coviello [20] argued that entrepreneurs engage in purposeful actions that are influenced predominately by forces external to a venture or network, affecting performance and business effectiveness [47]. Hence, the present thesis focuses on the impact of network relationships, and how firms strategize networks and resources towards sustaining business, via acquisition and management of knowledge and organizational capability.

Stafford et al., [21] recognized the importance and the multi-dimensionality of bonding, bridging network relationships, social capital, and knowledge and resource transactions during times of stability and change. Social capital can have positive or even negative effects on firm performance, suggesting that network relationships differentially affect business viability and sustainability. In this thesis, business growth and responsiveness to change are employed as measures of business performance, reflecting level of sustainable entrepreneurial development.

\section{Measures of SMEs Performance}

In this study, business growth and responsiveness to change are employed as measures of business performance, as suggested by Stafford et al., [21].

\section{Business Growth}

Anderson, Dodd, and Jack [48] posited that network relationships and trust develop over time, helping to foster growth. These investigators identified five patterns of network activity (i.e., liberating, inspiring, visioning, articulating, implementing) that enable growth in enterprises. Processes of growth are recognised as complex and are an essential characteristic of entrepreneurial behavior. Accordingly, in this thesis, growth intentions/aspirations and willingness to grow are used as measures of firm development [49].

Entrepreneurial strategic management approaches to small business are different to those of large organizations [50-52]. Organizational growth means more than just an increase in size [51]. Although organizations grow as a coherent whole, growth is best understood as being multi-faceted. In line with this view, Snyman [50] concluded that given the multi-faceted nature of organizations, entrepreneurs needed to constantly view the growth and development of their venture from a number of different perspectives.

In regards to growth of new ventures and small businesses, a number of perspectives should be taken into consideration: financial, strategic, structural, and organizational [50]; attitudes towards growth and growth opportunities [52]; and entrepreneurial spirit, strategic thinking, possibility of growth [53].

\section{Responsiveness to Change}

Firms are affected by environmental and structural changes [21]. According to Wang and Ahmed [54], organizational capabilities influence long-term business performance. Verdú and Gómez-Gras [55] proposed that responsiveness to change can be regarded as an organizational capability, enabling companies to face environmental fluctuations. Supporting this notion, Maguire, Koh and Magrys [56] noted that flexibility, agility and responsiveness to change and uncertainty are vital for creating sustainable, long-term competitive advantage, growth and survival.

\section{Networking and Performance of SMEs}

According to the structural approach, the context in which firms operate, together with their intrinsic characteristics and position in the network, can deeply influence the potential outcome, as highlighted by Gulati [57], Gulati and Higgins [58], Huggins [59] and Szarka [60]. These aspects have been implicitly investigated in different papers, but rigorous empirical tests on the effects of the socio-economic environment and on different network characteristics on members' economic performances are still lacking. Cisi, Devicienti, Manello and Vannani [3] propose different hypotheses on different structural aspects that can influence the economic outcome of networking. Firstly, they think that structural differences among firms can influence both the motivation and the economic impact of networking. They tested such idea empirically by dividing small and medium SMEs. In fact, larger SMEs (i.e. with more than 50 employees) can already exploit some benefits from scale economies, while smaller SMEs can benefit more from sharing resources in operational activities so as to overcome inefficiencies due to small size. On the contrary, larger SMEs may be more interested in sharing experiences or resources for making business abroad and opening new opportunities.

Networking with the right people is a crucial aspect in any network structure. Koch [61] stated that a firms' success mainly derives from professional relationships. Gulati and Higgins [58] argued that a person cannot succeed alone thus there is a trade-off between quality and quantity in business relationships and argues that the highest value is found in a small percentage of people in the personal network. The right people are not only those who possess expertise rather business associates also have to match the personality of the entrepreneur. The right business relationships are those where a good mutual understanding arise [62]. 
Network includes the combination of time, mutual trust and reciprocal services [63]. Ahuja [38], argues that the closer the relationship among members, the faster the speed of sharing resources. The more familiar contacts are, the more trustworthy the members become, and this reduces unethical behavior and encourages exchange amongst group members [64]. Through use of networks firms are capable of locating resources and hence the acquisition can be enhanced through mutual trust. Mutual trust therefore can gel members together hence contributing to firms performance [65].

A network of important contacts can provide help and resources to the company [66]. Networking, collaborations, partnerships, or alliances will provide the entrepreneur with access to other people's contacts [62]. This will lead to an expanded web of contacts which will eventually result in recognition of new opportunities and a larger network of clients and customers. Entrepreneurship is a dynamic process and requires links and relationships to both individuals and institutions [67]. In fact, an entrepreneur with a strong, complex and diverse network of relationships is more likely to have access to more opportunities, the chance of solving problems faster is greater, and the chance of success is greater [67]. Ventures should establish the number of nonredundant contacts in the network, in order to maximize connections with different people beyond the network that gives higher benefits because of more and preferably diverse contacts. As a result more diverse sources of information, resources and competences necessary for the venture to be efficient are ensured. In addition, ventures should recognize connections as ports of access to more diverse and separate clusters of people that are beneficial for a venture. Here the actor or the venture maintains the primary contacts who in turn reach other people (secondary contacts) in other clusters so that an extension to include new clusters of the ventures own network can be made. The venture is then free to focus on primary contacts and thus has more time for effectiveness that is, to do the right things. As Burt [24] puts it that information screen provided by multiple clusters of contacts is broader, providing better assurance of the players being informed of opportunities and impending disasters. From the foregoing, the following hypotheses have been set in null form:

- There is no significant effect of network structure on performance of Small and Medium Scale Enterprises in Benue State, Nigeria.

- There is no significant effect of network governance on performance of Small and Medium Scale Enterprises in Benue State, Nigeria.

- There is no significant effect of network content on performance of Small and Medium Scale Enterprises in Benue State, Nigeria.

\section{Methodology}

The study adopted the survey research design due to its ease of application and the speed with which its results are ready. The target population for this study consists of 708 owners/senior management staff of SMEs in Makurdi metropolis in Benue State, Nigeria. These consisted of different sectors like food processing (24), livestock rearing (32), schools (86) trading (164), art/craft (42), baking (34), table water (17), fashion and designing/ hair dressing (97), ICT (92), health (65) and transportation (55). 256 respondents were sampled. The questionnaire was used as the research tool for data collection. The research tool consists of two 4-point Likert questionnaires. Cronbach alpha was used to test the reliability of the research tool. This method calculates the internal consistency of those research tools measuring several criteria. Cronbach alpha values for all the coefficients were higher than the threshold 0.70 , i.e. we can confirm the reliability of the research tool. To test the construct validity of research variables, we used exploratory factor analysis by principal factors with warimax rotation. Factor loadings were more than 0.5 and so were considered as high and acceptable. The 256 questionnaires administered met a 0.83 response rate and 213 questionnaires were used for statistical analysis. With the aid of SPSS version 21, multiple regression analysis was used to test the strength of the effect of network dimensions on performance of SMEs.

The study is anchored on two variables; the independent variable (networking) and the dependent variable (SMEs performance). The independent variable is measured in terms of network structure, network governance and network content. The dependent variable (SMEs performance) on the other hand is measured based on sales growth and responsiveness to change.

This study suggests that SMEs performance is a function of Networking;

SMEsP $=f(N w)$ (i)

Where,

SMEsP = SMEs Performance (dependent variable)

$\mathrm{Nw}=$ Networking (independent variable)

Given that networking comprises three dimensions, the implicit form of the model is given as follows:

SMEsP = $f(\mathrm{Ns} . \mathrm{Ng}, \mathrm{Nc}$ )

Where,

Ns = Network structure;

$\mathrm{Ng}=$ Network governance; and

$\mathrm{Nc}=$ Network content 
Thus, the explicit form of the model for the study will be as follows:

SMESP $=a+b_{1} \mathrm{Ns}_{1}+b_{2} \mathrm{Ng}+b_{3} \mathrm{Nc}+\varepsilon$

Where,

$a=$ Intercept of the Model (constant)

$b_{1}$ to $b_{3}=$ coefficients of $\mathrm{Ns}, \mathrm{Ng}, \ldots . . . \mathrm{Nc}$ respectively

$\varepsilon=$ error term

Other variables are as earlier defined.

\section{RESULTS}

\section{Regression Analysis Result}

The result of the regression analysis carried out was presented under the model summary, Analysis of Variance (ANOVA) and regression coefficient.

Table-1: Model Summary

\begin{tabular}{|l|l|l|l|l|}
\hline $\mathbf{R}$ & R-Square & Adjusted R Square & Std. Error of the Estimate & Durbin-Watson \\
\hline .627 & .393 & .361 & .65816 & 1.766 \\
\hline \multicolumn{4}{|}{ a. Predictors (Constant), Network content, Network governance, Network structure } \\
b. Dependent Variable: SMEs Performance
\end{tabular}

Source: Field Data, 2019.

The result from Table-1 shows that coefficient of determination ( $R$ square) explains the variation in the dependent variable due to changes in the independent variable. The $\mathrm{R}$ square value of 0.393 is an indication that there was variation of $39.3 \%$ in performance due to changes in network structure, network governance and network content at $95 \%$ confidence interval. Also, the value of $\mathrm{R}$ from Table-1 shows the relationship between the study variables which implies that there was a strong positive relationship between the study variables as shown by 0.627 .

Table-2: ANOVA Model

\begin{tabular}{|l|l|l|l|l|l|}
\hline & Sum of Squares & df & Mean Square & F & Sig. \\
\hline Regression & 21.062 & 3 & 5.265 & 12.155 & $.000^{\mathrm{b}}$ \\
\hline Residual & 32.488 & 109 & .433 & & \\
\hline Total & 53.550 & 212 & & & \\
\hline \multicolumn{6}{|l|}{ C. Dependent Variable: SMEs Performance } \\
d. Predictors (Constant), Network content, Network governance, Network structure
\end{tabular}

Source: Field Data, 2019.

The result from the ANOVA statistics in Table-2 indicates that the processed data, which is the population parameters, had a significance level of 0.000 which shows that the data is ideal for making a conclusion on the population's parameter as the value of significance ( $p$-value) is less than $5 \%$. This implies that network content, network governance and network structure significantly influence the performance of SMEs in Makurdi metropolis The significance value was less than 0.05 which indicates that the model was statistically significant $(F=12.155 ; P=.000)$.

Table-3: Regression Coefficients

\begin{tabular}{|c|c|c|c|c|c|c|c|}
\hline \multicolumn{9}{|c|}{ Unstandardized Coefficients } & \multicolumn{3}{c|}{ Standardized Coefficients } \\
\hline B & Std. Error & Beta & $\mathbf{t}$ & Sig. & Tolerance & VIF & Decision \\
\hline (Constant) & .754 & .434 & & 1.737 & .086 & & \\
\hline Structure & .274 & .128 & .231 & 2.143 & .035 & .697 & Rejected \\
\hline Governance & .477 & .087 & .530 & 5.477 & .000 & .795 & Rejected \\
\hline Content & .201 & .107 & .1901 & 1.886 & .043 & .864 & Rejected \\
\hline a. Dependent Variable: SMEs Performance
\end{tabular}

Source: Field Data, 2019.

From the data in the Table-3 the established regression equation SMEsP $=a+b_{1} N s_{1}+b_{2} \mathrm{Ng}+b_{3} \mathrm{Nc}$ is presented thus: SMEsP $=0.754+0.274$ (Network structure) +0.477 (Network governance) +0.201 (Network content) +0.251 .

The regression equation above revealed that holding network structure, network governance and network content to a constant zero, SMEs performance would be 0.754 , a unit increase in network structure would affect performance by a factor of 0.274 , a unit increase in network governance would affect performance by $47.7 \%$ and a unit increase in network content would affect 
performance by $20.1 \%$. The study also found that the $p$-values of network structure, network governance and network content $(.035$, $.000, .043)$ respectively were less than 0.05 . Furthermore, the result of the analysis shows that network content has more significant effect on the performance of SMEs in Makurdi metropolis.

The three hypotheses formulated in this study were tested as follows:

To test the first hypothesis, the strength of the effect of network structure on performance of SMEs was measured by the calculated $p$-value $=0.035$ at a significance level $(a)$ of 0.05 . Since the computed $p$-value is less than the significance level $(\alpha)$ of 0.05 $(p$-value $0.035<a 0.05)$, the null hypothesis was rejected. It is therefore concluded that network structure has significant effect on performance of SMEs in Makurdi metropolis.

To test the second hypothesis, the strength of the effect of network governance on SMEs performance was measured by the calculated $p$-value $=0.000$ at a significance level (a) of 0.05 . Since the computed $p$-value is less than the significance level ( $a$ ) of 0.05 $(p$-value $0.000<a 0.05)$, the null hypothesis was rejected. It is therefore concluded that network governance has significant effect on the performance of SMEs in Makurdi metropolis.

To test the third hypothesis, the strength of the effect of network content on SMEs performance was measured by the calculated $p$-value $=0.043$ at a significance level (a) of 0.05 . Since the computed $p$-value is less than the significance level ( $\alpha$ ) of 0.05 ( $p$-value $0.043<a 0.05)$, the null hypothesis was rejected. It is therefore concluded that network content has significant effect on the performance of SMEs in Makurdi metropolis.

\section{DISCUSSION}

This study examined the effect of networking on the performance of SMEs in Benue State, Nigeria. The findings in this study showed that networking significantly affects SMEs performance in Makurdi metropolis.

The result of the finding revealed a significant effect of network structure on performance of Small and Medium Scale Enterprises in Benue State, Nigeria. Regression analysis was used for test of hypothesis and this is statistically presented as $(P=$ $.035<0.05)$. This agrees with the finding by Gulati and Higgins [58] found that a person cannot succeed alone thus there is a trade-off between quality and quantity in business relationships and argues that the highest value is found in a small percentage of people in the personal network. The study also agrees with Cisi, Devicienti, Manello, and Vannoni [3], who found that network characteristics, such as size, geographical dispersion and diversity, are also found to influence performance. The finding however disagrees with Korir, Maru, Kipruto, and Koskei [68] who found that network structure does not affect venture performance.

The finding from objective two also revealed a significant effect of network governance on performance of Small and Medium Scale Enterprises in Benue State, Nigeria. Regression analysis was used for test of hypothesis and this is statistically presented as $(P=.000<0.05)$. This finding is in agreement with earlier findings reported by scholars such as Ahuja (2000) who argues that the closer the relationship among members, the faster the speed of sharing resources and Gulati [64] who found that the more familiar contacts are, the more trustworthy the members become, and this reduces unethical behavior and encourages exchange amongst group members.

This finding revealed a significant effect of network content on performance of Small and Medium Scale Enterprises in Benue State, Nigeria. Regression analysis was used for test of hypothesis and this is statistically presented as $(P=.043<0.05)$. This agrees with the findings by Smilor and Gill [67] which stated that an entrepreneur with a strong, complex and diverse network of relationships is more likely to have access to more opportunities, the chance of solving problems faster is greater, and the chance of success is greater.

\section{IMPLICATION OF THE FINDINGS}

The findings of this study imply that whether a firm likes it or not, it is embedded in a network of business relationships. These network relationships can both enable and constrain its performance as it seeks to meet its economic goals. As such, firms are not seen in isolation but as connected in business systems. The practice of networking within a business to business (b2b) environment is not new and, judging by the growing number of business networking groups, it is apparently increasing in popularity.

\section{DIRECTION FOR FUTURE RESEARCH}

It is suggested that further studies should be carried out on the effect of networking on financial performance of SMEs to ascertain if the effect will be same like that of none financial performance. Further research should be carried out applying the same variables in different sectors of the economy like the banking industry. And finally, other authors should carryout compressive research using interviews and open-ended questions to enable the respondents share their views and opinions as regards the topic. 


\section{CONCLUSION}

Networking in a business environment bothers on network structure, network governance and network content which form the basis upon which SMEs interact with its environment. This study examined the effect of networking on performance of SMEs in Benue state, Nigeria. Based on findings, the study concludes that performance of SMEs is affected by networking. That the structure manner and content of networks a firm maintains have a great effect on its performance. The study recommends that: SMEs operating in Benue state should set up a formation structure that will allow them interact freely with their environment; Management of SMEs should be mindful of how they handle the networks thereby being sincere and truthful so as not to loose the benefits of networking. And finally, management should be mindful of the content of their network since the network content has a significant effect on performance of SMEs.

\section{References}

1. Sussan, A. P., \& Johnson, W. C. (2003). Strategic capabilities of business process: looking for competitive advantage.

2. Johnson, G., \& Scholes, K. (2005). 'Exploring Corporate Strategy', 7th ed., India: Pearson Education (Singapore) Pte. Ltd.

3. Cisi, M., Devicienti, F., Manello, A., \& Vannoni, D. (2016). Impact of formal networking on the performance of SMEs, Collegio Carlo Alberto Research working paper No. 490.

4. Leifer, I., Luyendyk, B. P., Boles, J., \& Clark, J. F. (2006). Natural marine seepage blowout: Contribution to atmospheric methane. Global Biogeochemical Cycles, 20(3).

5. Nyangarika, A. (2016) Impact of Networking on Performance of Small and Medium Enterprises in Tanzania, European Journal of Business and Management, 8(6):48-57.

6. Lorenzoni, G., \& Baden-Fuller, C. (1995). Creating a strategic center to manage a web of partners. California management review, 37(3), 146-163.

7. Maina, J. N., Marwa, S. M., Waiguchu, M., \& Riro, G. K. (2016). Network relationships and firm performance: an empirical study of Kenyan manufacturing firms, International Journal of Economics, Commerce and Management United Kingdom, 6(3):258272.

8. Casson, M., \& Giusta, M. D. (2007). Entrepreneurship and social capital: analysing the impact of social networks on entrepreneurial activity from a rational action perspective. International Small Business Journal, 25(3):220-244.

9. Gulati, R., \& Garino, J. (2000). Get the right mix of bricks \& clicks. Harvard business review, 78(3), 107-107.

10. Dyer, W. G., \& Whetten, D. A. (2006). Family firms and social responsibility: Preliminary evidence from the S \& P 500. Entrepreneurship Theory and Practice, 30, 785-802

11. George, G., Zahra, S. A., Wheatley, K. K., \& Khan, R. (2001). The effects of alliance portfolio characteristics and absorptive capacity on performance. A study of biotechnology firms. The Journal of High Technology Management Research, 12: 205-226.

12. Chetty, S. K., \& Wilson, H. I. M. (2003). Collaborating with competitors to acquire resources. International Business Review, 12(1):61-81.

13. OECD. (2004). Promoting entrepreneurship and Innovative SMES in a global economy: Towards a more responsible and inclusive globalization.

14. UNIDO. (2005). Methodology development of SMEs supplier networks, Abridged version, Vienna, 1-3

15. Machirori, T. L. (2012). Impact of networking on access to finance and performance of SMEs in the Buffalo City Municipality, Eastern Cape, South Africa: Doctoral Dissertation, submitted to the University of Fort Hare.

16. Lorna, U. (2007). How to promote competitive Advantages for SMEs: Issues, Ideas and Innovation, Journal of Business Systems, Governance and Ethics, 2(2):43-49

17. Ogunnaike, O. O., \& Kehinde, O. J. (2013). Social networking and business performance: The case of selected entrepreneurs in Ota, Nigeria Journal of Business Administration and Management Sciences Research. 2(5):116-122.

18. Hoang, H., \& Antoncic, B. (2003). Network-based research in entrepreneurship a critical review. Journal of Business Venturing, 18(2): 165-187.

19. Amit, R., \& Zott, C. (2001). 'Value creation in e-business', Strategic Management Journal, 22:493-520

20. Slotte-Kock, S., \& Coviello, N. (2010). Entrepreneurship Research on Network Processes: A Review and Ways Forward. Entrepreneurship Theory and Practice, 34(1):31-57

21. Stafford, K., Bhargava, V., Danes, S., Haynes, G., \& Brewton, K. (2010). Factors Associated with Long-Term Survival of Family Businesses: Duration Analysis. Journal of Family and Economic Issues, 31(4):442-457

22. Moreno, J. (1937). Sociometry in relation to other social sciences. Sociometry, 1(1):206-219.

23. Coleman, J. S. (1988). Supplement: Organizations and institutions: Sociological and economic approaches to the analysis of social structure. American Journal of Social Sciences, 94: 95-120.

24. Burt, R. S. (1992). Structural holes, the social structure of competition. Cambridge, MA: Harvard University Press.

25. Burt, R. S. (1997). The contingent value of social capital. Administrative Science Quarterly, 42(2): 339-365.

26. Carson, M. R., \& Welsh, M. J. (1995). Structural and functional similarities between the nucleotide-binding domains of CFTR and GTP-binding proteins. Biophysical journal, 69(6), 2443-2448.

27. Conway, S., Jones, O., \& Steward, F. (2001). Realising the potential of the social network perspective in innovation studies. In O. Jones, S. Conway, \& F. Steward (Eds.), Social interaction and organizational change: Aston perspectives on innovation networks (pp. 349-366). London: Imperial College Press. 
28. Conway, S., \& Jones, O. (2006). Networking and the small business. In S. Carter \& D. Jones Evans (Eds.), Enterprise and small business. Harlow: Prentice Hall.40 2 Strategic Networks, Trust and the Competitive Advantage of SMEs

29. Ford, D., Gadde, L., Hakansson, H., \& Snehota L. (2003), Managing Business Relationships Chichester, England: Wiley \& Sons Ltd.

30. Nohria, N., \& Rober, G. E. (1992), Networks and Organisations, Structures, Forms and Action. Boston MA: Harvard Business School Press.

31. Jack, S., Dodd, S. D., \& Anderson, A. R. (2008). Change and the development of entrepreneurial networks over time: a processual perspective. Journal of Entrepreneurship \& Regional Development, 20(2):125-159.

32. Street, C. T., \& Cameron, A. (2007). External relationships and the small business: a review of small business alliance and network research. Journal of Small Business Management, 45(2): 239-266.

33. Allee, V. (2008). Value network analysis and value conversion of tangible and intangible assets. Journal of Intellectual Capital, 9(1): 5-24.

34. Adler, P. S., \& Kwon, S. (2002). Social Capital: Prospects for a New Concept. The Academy of Management Review, 27(1):1740.

35. Moran, P. (2005). Structural vs. relational embeddedness: social capital and managerial performance. Strategic Management Journal, 26(12), 1129-1151.

36. Zaheer, A., \& Bell, G. G. (2005). Benefiting from network position: firm capabilities, structural holes, and performance. Strategic Management Journal, 26(1):809-825.

37. McEvily, B., \& Marcus, A. (2005). Embedded ties and the acquisition of competitive capabilities. Strategic management journal, 26(11), 1033-1055.

38. Ahuja, G. (2000). Collaboration network, structural holes, and innovation: A longitudinal study. Administrative Science Quarterly 45 (3): 425-55

39. Burt, M. R., Aron, L. Y., \& Lee, E. (2001). Helping America's homeless: Emergency shelter or affordable housing?. The Urban Insitute.

40. Lee, C., Lee, K., \& Pennings, J. M. (2001). Internal capabilities, external networks, and performance: a study on technologybased ventures. Strategic Management Journal, 22(6-7): 615-640.

41. Larson, L. M., Suzuki, L. A., Gillespie, K. N., Potenza, M. T., Bechtel, M. A., \& Toulouse, A. L. (1992). Development and validation of the counseling self-estimate inventory. Journal of Counseling Psychology, 39(1), 105.

42. Watson, J. T., \& Sparkman, O. D. (2007). Introduction to mass spectrometry: instrumentation, applications, and strategies for data interpretation. John Wiley \& Sons.

43. Starr, J. A., \& MacMillan, I. C. (1990). Resource cooptation via social contracting: Resource acquisition strategies for new ventures. Strategic Management Journal, 79-92.

44. Brüderl, J., \& Preisendörfer, P. (1998). Network support and the success of newly founded business. Small business economics, 10(3), 213-225.

45. Elfring, T., \& Hulsink, W. (2003). Networks in entrepreneurship: The case of high-technology firms. Small business economics, 21(4), 409-422.

46. Smeltzer, M. F. (1991). U.S. Patent No. 5,064,371. Washington, DC: U.S. Patent and Trademark Office.

47. Barlatier, P. J., \& Giannopoulou, E. (2011). The dual perspective of sustainable development in service innovation: A conceptual model proposition for research and technology organizations.

48. Anderson, A., Drakopoulou Dodd, S., \& Jack, S. (2009). Aggressors; winners; victims and outsiders: European schools' social construction of the entrepreneur. International Small Business Journal, 27(1), 126-136.

49. Achtenhagen, L., Naldi, L., \& Melin, L. (2010). "Business Growth"-Do Practitioners and Scholars Really Talk About the Same Thing, Journal of Entrepreneurship Theory and Practice, 34(2), 289-316.

50. Snyman, D. C. (2003). An Exploration of Market Growth and Development Strategies for Franchising a Selected Fast Food Outlet. Magister in Business Administration. Nelson Mandela Multimedia University.

51. Wickham, P. A. (1998). Managing the growth and development of the venture: Strategic entrepreneurship. London: Pitman Publishing.

52. Wiklund, J., Patzelt, H., \& Shepherd, D. (2009). Building an integrative model of small business growth. Journal of Small Business Economics, 32(4):351-374.

53. Lazenby, J. A. A. (2004). Entrepreneurial Strategic Management: An Approach for Small Business Growth. Magister Manajemen. Ejournal Universitas Narotama. http://ejournal.narotama.ac.id/index.php/detail/3633/1111

54. Wang, C. L., \& Ahmed, P. K. (2007). Dynamic capabilities: A review and research agenda. International journal of management reviews, $9(1), 31-51$.

55. Verdú, A. J., \& Gómez-Gras, J. M. (2009). Measuring the organizational responsiveness through managerial flexibility. Journal of Organizational Change Management, 22(6):668-690.

56. Maguire, S., Koh, S. C. L., \& Magrys, A. (2007). The adoption of e-business and knowledge management in SMEs. Benchmarking: International Journal of management, 14(1): 37-58.

57. Gulati R. (1998). Alliances and networks. Strategic Management Journal, 19(4):293-317.

58. Gulati, R., \& Higgins, M. (2003). Which ties matter when? The contingent effects of inter-organizational partnerships on IPO success. Strategic Management Journal, 24(2):127-144. 
59. Huggins, R. (2000). The success and failure of policy-implanted inter-firm network initiatives: motivations, processes and structure. Entrepreneurship and Regional Development, 12(2):111-135.

60. Szarka, J. (1990). Networking and small firms. International Small Business Journal, 8:10-22.

61. Koch, R. (1998). The 80/20 Principle: The secret of achieving more with less. New York: Doubleday.

62. Edwards, P., Edwards, S., \& Benzel, R. (2007). Teming up: The small-business guide to collaborating with others to boost your earnings and expand your Horizons. New York: G.P. Putnam's Sons.

63. Granovetter, M. S. (1973). The strength of weak ties. American Journal of Sociology, 78:1360-1380.

64. Gulati, R. (1995). Does familiarity breed trust? The implications of repeated ties for contractual choice in alliances. Academy of management journal, 38(1), 85-112.

65. Uzzi, B. (1996). The sources and consequences of embeddedness for the economic performance of organizations: The network effect. American sociological review, 674-698.

66. Wallace, E. (2006). Fares to Friends: How to Develop Outstanding Business Relationships. USA: The Relational Capital Group.

67. Smilor, R., \& Gill, M. (1986). The New Business Incubator: Linking Talent, Technology, Capital, and Know-How. Massachusetts: Lexington Books DC Health and Company.

68. Korir, J., Maru, L., Kipruto, N., \& Koskei, D. (2012). Effects of network structure on performance of minor event management ventures in Kenya, European Journal of Business and Social Sciences, 1(6):34-45. 